\title{
Students' perception on seminars: a questionnaire study
}

\author{
Kothari Ruchi ${ }^{1}$, Bokariya Pradeep ${ }^{2}$, Shende $M R^{3}$, Singh Ramji ${ }^{4}$
}

\begin{abstract}
Introduction: Considering the rising intellect of students and the developing scientific temper among undergraduates the concept of seminars was introduced to first year MBBS students. The innovative approach (concept of seminar) for the learning of first year medical subjects needs to be evaluated periodically. A questionnaire was designed to obtain feedback from students.
\end{abstract}

Methods: First year medical students were given a questionnaire comprising of eleven questions.

Results: The views obtained by students were calculated as percentage and discussed.

Conclusion: The majority of students has considered it to be good method of self-learning and were in support of continuation of such a system in forthcoming years.

\section{Introduction}

Innovations in medical education have become the need of the hour. With recent advancement in techniques for teachers and considering the wider intellect of medical student, we must welcome alternative methods of teaching apart from didactic lecture (Hayes, N., 2000; Schuwirth, 2004)

Keeping all these things in mind we at Mahatma Gandhi Institute of Medical Sciences (MGIMS), Sevagram has introduced a concept of seminars for first year student under the Academy of Basic Medical Sciences. All the students of MBBS first year chose the topic pertaining to anatomy, physiology and biochemistry students prepared a topic, and talked about it students developed a habit to find appropriate literature and used good communication skills. Keeping these points in mind and seeing their improvement in examinations, it was pertinent to conduct this study.

\footnotetext{
${ }^{1}$ Assistant Professor, Department of Physiology

${ }^{2}$ Assistant Professor, Department of Anatomy

${ }^{3}$ Professor and Head, Department of Anatomy

${ }^{4}$ Professor and Head, Department of Physiology

Mahatma Gandhi Institute of Medical Sciences

Corresponding author:

Pradeep Bokariya

Department of Anatomy

Mahatma Gandhi Institute of Medical Sciences

Sevagram, Wardha, India 442102

Ph:+919730942676
}

Considering all these facts we conducted a survey for first year MBBS. Students were active participation in the survey.

\section{Aims \& Objectives}

The main objectives of the survey were to investigate students' view on various aspects of seminars and their suggestions to make it better.

\section{Material \& Methods}

The permission to conduct this study was obtained from the institutional ethics committee. An informed consent from was completed by students of MGIMS, and Sevagram for their involvement in survey. A questionnaire had been given to 55 students where they were supposed to write their views about seminars. The questionnaire consisted of the points. In which students choices are: below, strongly agree, below, agree, strongly disagree and disagree are as follows:

1. Seminars are always informative.

2. Preparation requires more than 2 days.

3. Classmates are always help.

4. You will opt for topic which is not covered in class.

5. Should be incorporated in curriculum by the university.

6. You should read topic before the seminar.

7. You should read about the topic after seminars. 
8. It is a good way of revision.

9. It is a good source of extra knowledge.

10. You should discuss the topic with class mates.

11. Hesitation of public speaking diminishes.

Students were requested to write their views on the advantages and disadvantages of the system and their valuable suggestions to make it better. The result obtained was analyzed using MS Excel and the results were calculated on percentile89.

\section{Result}

The views obtained from the students were calculated in percentile which is shown in Figure 1. Ninety four percent students found it to be informative $(42 \%$ strongly agree and $53 \%$ agree), whereas, only six percent were against this (4\% strongly disagree and $2 \%$ disagree). Similarly, the majority of them (55\% strongly agree and 33\% agree) have shown higher degree of agree when asked about preparation time (if more than 2 days) and assistance provided by classmates (38\% strongly agree and $55 \%$ agree). Eighty nine percent considered it to be a good source of extra knowledge while percent don't think so. It is good way of revision according to $90 \%$ of them. Mixed responses were observed when enquired about inclusion of the system in the university curriculum $(62 \%$ in favor and $38 \%$ against), opting the topic not covered in the class (16\% strongly agree, $30 \%$ agree, $16 \%$ strongly disagree and $36 \%$ disagree). There were $70 \%$ of the students who agreed that they read the topic before the seminar; whereas, fifty percent pupils read it after the topic was taught. Around $88 \%$ (56\% strongly agree and $31 \%$ agree) students believe that it diminishes their hesitation to public speaking, while around $12 \%$ ( $5 \%$ strongly disagree and $7 \%$ disagree) of students were against it.

Figure 1: Showing students' views on perception of incorporation of seminars in their curriculum.

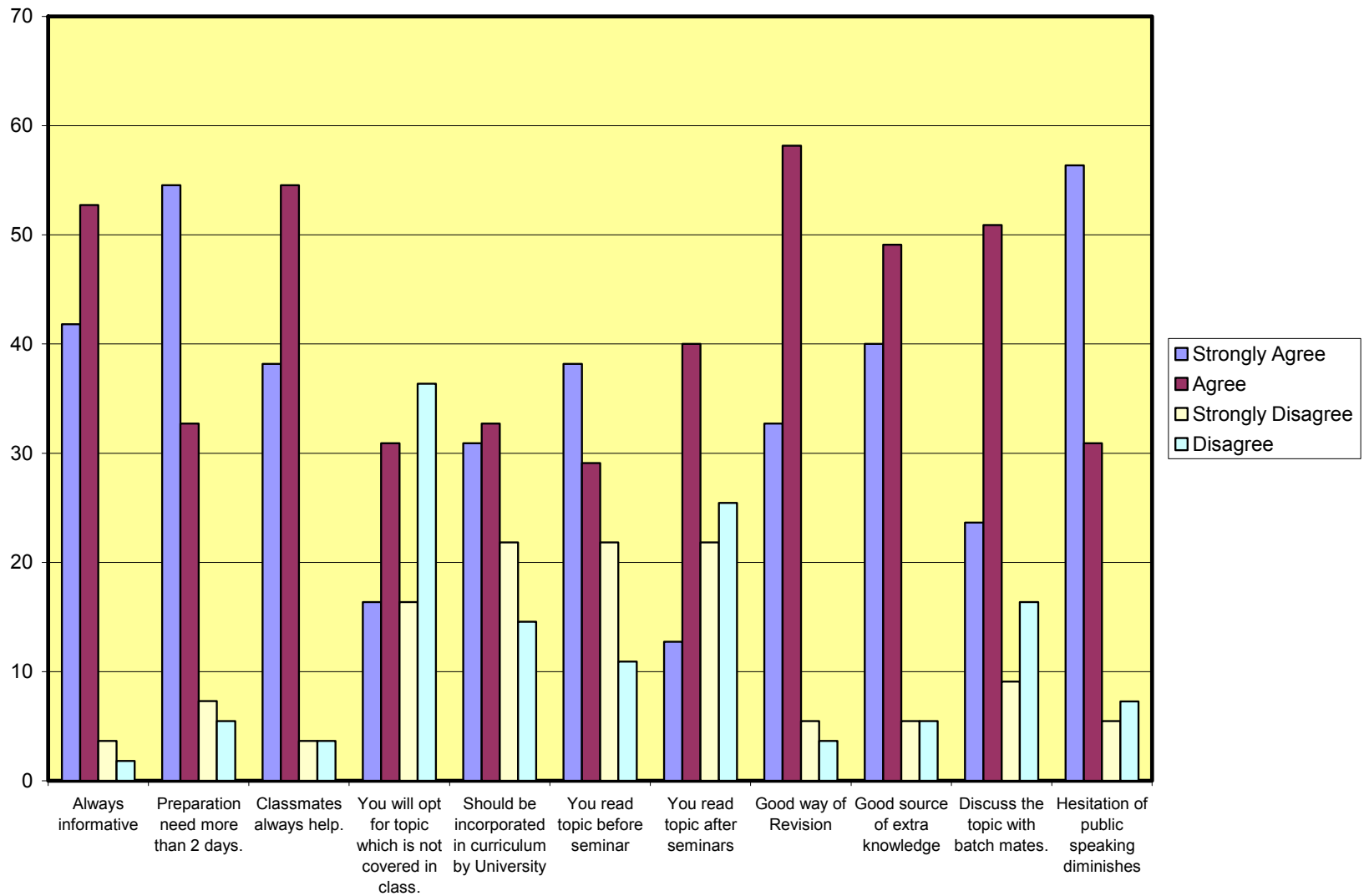

The $\mathrm{X}$ axis represents lists of questions asked and $\mathrm{Y}$ axis represents the percentages of students. 


\section{Discussion}

The students were enthusiastic with the concept of seminars and found it to be a good tool for learning subjects with their lectures. Student teaching students in front of their teachers was a novel concept. The majority of the students welcomed such innovations and expressed their view that such system should continue in the forthcoming years. We were interested in knowing how much time is required by students in the preparation of a seminar; that's why question number 2 was added. Similarly a few questions were framed to investigate team efforts, and the role of seminars in revising topics. The students reply has boosted faculty is moral which was pointed out by previous researchers also (Schwarz, 2002; Wake ford, 1981; and Brownell, 2007).

Sometimes students opted for topics not taught such as the heart, and the spinal cord. Delivering a seminar presentation on the same topic has increased the confidence in students' performance and in their examinations. Most of the students liked the concept but were in hesitation to include it in their curriculum due to the time factor. The situations are entirely different when teaching in India (Gupta, 2003; Doe, 2004).

The efforts students put in preparation of seminars were extraordinary. The short duration of the academic year of I MBBS was matter of great concern among student and faculty members may constraint faculty members to implement it.

The United Kingdom (Williams, 2004) has undergone significant curriculum reform in undergraduate medical teaching over the past decade, including a transformation from the didactic teaching of factual knowledge to a more problem based learning methodology, utilizing and promoting students' initiative.

\section{Conclusion}

Learning is not a spectator sport. Students do not learn much just sitting in class listening to teachers, memorizing pre-packed assignments and spitting out the answers. We feel that implementation of student's seminars as a revision exercise should be explored as a teaching \& learning method after knowing the views of students. The fact that it was equally beneficial for all students adds to its usefulness.

\section{Reference}

Brownell, A.M. (2007) A peer reviewed collection of reports on innovative approaches to medical education, Med Edu, 41, 5, pp. 505-06.

Deo, M.G., Gangal, S.G., Kher, A. \& Muranjan, M. (2004) Mobile workshops for students - A novel programmed for graduate medical education, Curr Sci, 86, pp. 1377-80.

Gupta, P., Kumhar, G. \& Shah, D. (2003) Alternative learning strategies, Indian Pediatr, 40, pp. 731-41.

Hayes, N. (2000) Doing psychological research: gathering and analyzing data. Open University Press Buckingham

Schuwirth, L. \& Vleuten, C. (2004) Merging views on assessment, Medical Education, 38, 12, pp. 1208-11.

Schwarz, M.R. \& Wojtczak, A. (2002) Global minimum essential requirements: a road towards competence oriented medical education, Medical Teacher, 24, 2, pp. 125-9.

Wakeford, R. (1981) Students' perception of the medical school learning environment: a pilot study into some differences and similarities between clinical schools in the UK, Assessment and Evaluation in Higher Education, 6, 3, pp. 206-17

Williams, G. \& Lau, A. (2004) Reform of undergraduate medical teaching in the United Kingdom: a triumph of evangelism over common sense, British Medical Journal, 329, 7457, pp. 92-94 